\title{
Carnets
}

Revue électronique d'études françaises de l'APEF

Première Série - 3 Numéro Spécial | 2011

La littérature face au "politiquement correct». Notions, pratiques et dérives

\section{Michel Houellebecq et Jacques Chessex : parcours singuliers du politiquement incorrect Zones de partage et lignes de fuite}

\section{Corina da Rocha Soares}

\section{(2) OpenEdition}

\section{Journals}

Édition électronique

URL : http://journals.openedition.org/carnets/6438

DOI : $10.4000 /$ carnets. 6438

ISSN : 1646-7698

Éditeur

APEF

Édition imprimée

Date de publication : 1 juin 2011

Pagination : 77-99

\section{Référence électronique}

Corina da Rocha Soares, « Michel Houellebecq et Jacques Chessex : parcours singuliers du

politiquement incorrect Zones de partage et lignes de fuite », Carnets [En ligne], Première Série - 3 Numéro Spécial | 2011, mis en ligne le 19 juin 2018, consulté le 01 mai 2019. URL : http:// journals.openedition.org/carnets/6438; DOI : 10.4000/carnets.6438

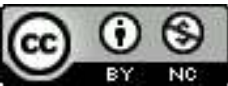

Carnets est mis à disposition selon les termes de la licence Creative Commons - Atribution - Pas d'utilisation commerciale 4.0 International. 


\title{
MICHEL HOUELLEBECQ ET JACQUES CHESSEX: PARCOURS SINGULIERS DU POLITIQUEMENT INCORRECT
}

Zones de partage et lignes de fuite

CORINA DA ROCHA SOARES

Universidade de Aveiro; F.C.T.

cgwenaelle@gmail.com

\begin{abstract}
Résumé
Michel Houellebecq et Jacques Chessex sont deux succès littéraires contemporains qu'apparemment tout oppose: le premier, français, est un scientiste citadin, dont le style plat est en accord avec sa vision dépressive du monde; le second, suisse, est un métaphysicien amoureux de la nature, qui manie avec virtuosité une prose lyrique afin d'exprimer des passions ardentes. Pourtant, ils ont tous deux utilisé leur plume comme un acte d' "irrévérence sociale" axé sur ce qu'il ne "convient pas socialement d'écrire", en parallèle avec une posture médiatique sui generis. Deux parcours singuliers du politiquement incorrect dont nous tâcherons d'analyser les zones de partage et les lignes de fuite.
\end{abstract}

\begin{abstract}
Michel Houellebecq and Jacques Chessex are two contemporary literary successes, apparently opposed in everything: the first one, French, is an urban writer, faithful to scientism, with a flat style that is according to his depressive vision of the world; the second one, Swiss, is a metaphysician passionate about nature, who uses with virtuosity a lyric prose to express fiery passions. However, they both use their pen as an act of "social irreverence" turned to what "it's not socially convenient to write", in parallel with a sui generis mediatic posture. Two singular careers of the politically incorrect whose sharing zones and escape lines we will try to analyse.
\end{abstract}

Mots-clés: Jacques Chessex, Michel Houellebecq, postures outrageantes Keywords: Jacques Chessex, Michel Houellebecq, outrageous postures 
Quant aux écrivains qui s'obstinent à vivre, on leur demande seulement de ne pas trop remuer et de s'appliquer à ressembler dès maintenant aux morts qu'ils seront.

Jean-Paul Sartre (1948),

Qu'est-ce que la littérature?

Eu não escrevo para agradar. Tão pouco para desagradar.

Eu escrevo para desassossegar.

José Saramago ${ }^{1}$

\section{Qu'entendons-nous par politiquement (in)correct?}

Les frontières du "politiquement correct" ne sont pas immuables: elles changent selon l'époque, l'actualité, l'air du temps; selon l'espace géographique, le milieu social. Elles dépendent aussi de la perspective de la personne qui émet les propos, mais aussi de celle qui les entend. Ainsi, un discours anti-musulman a des portées distinctes selon qu'il sera prononcé par un raciste ou un humoriste, ou selon qu'il sera intercepté par une victime d'un attentat islamiste ou un intégriste musulman.

Être politiquement incorrect revient à adopter des propos et des comportements qui heurtent les mœurs ou la morale de l'époque, les règles du savoir-vivre. Mais c'est aussi combattre la pensée dominante, se rebeller contre le conformisme ambiant. Revendiquer une liberté de ton, chercher une liberté de pensée au-delà des discours majoritaires. Aux plus modérés, on louera l'audace. Les autres courent le risque de choquer, de passer pour rebelles, d'être liés au scandale, à la provocation ou, pire, de devenir persona non grata.

C'est en pensant à tout ceci que nous vient naturellement à l'esprit le cas du romancier français Michel Houellebecq. Sa réputation le précède: écrivain sulfureux, accusé de pornographie gratuite, de propos misogynes et anti-islamistes; auteur de controverses médiatiques calculées... Et pourtant, considéré par beaucoup comme le plus grand romancier français contemporain.

II n'est pas le seul écrivain à avoir tracé ce parcours. De l'autre côté de la frontière, Jacques Chessex, "grantécrivain" de Suisse romande, alimentait la même réputation jusqu'à son décès en 2009. Michel Houellebecq et Jacques Chessex sont deux succès littéraires contemporains qu'apparemment tout oppose dans leur vision de l'existence, du rôle de

\footnotetext{
${ }^{1}$ Propos de José Saramago lors de la présentation de son roman Caïm, Conférence à Madrid, Casa América, 2 novembre 2009 [en ligne]. [consulté le 19/10/2010] <URL: http://www.youtube.com/watch?v=xVhxn96neG8>. Notre traduction.
} 
l'écrivain, du style de leur écriture. Pourtant, ils ont tous deux utilisé leur plume comme un acte d' "irrévérence sociale" axé sur ce qu'il ne "convient pas socialement d'écrire", en parallèle avec une posture médiatique sui generis. Deux parcours singuliers du politiquement incorrect dont nous allons tâcher de dégager les zones de partage et les lignes de fuite. Houellebecq, Chessex: chercher les différences ou trouver l'erreur...

\section{Brève présentation de Michel Houellebecq et de Jacques Chessex}

Presqu'une génération sépare Michel Houellebecq de Jacques Chessex, vingt ans son aîné. Celui-ci s'est d'ailleurs éteint, hélas, dans des conditions consternantes: un médecin qui, choqué de lire que Jacques Chessex qualifiait d'affaire "minime" le viol d'une mineure par Roman Polanski, l'a interpellé à Yverdon quelques secondes avant qu'il ne s'effondre, foudroyé par un arrêt cardiaque. Houellebecq, lui, est au sommet de sa gloire. Le prix Goncourt vient même de lui être attribué. II est pourtant l'auteur d'un petit nombre de romans longs, comparé à son homologue suisse à l'œuvre impressionnante: plus de 80 ouvrages, nouvelles et chroniques pour la plupart ${ }^{2}$.

Michel Houellebecq est tout de même l'écrivain français le plus exportable d'aujourd'hui. Le best-seller d'expression française par excellence. Une réussite dont n'a jamais pu profiter Jacques Chessex, même si sa consécration littéraire ne fait nul doute, légitimée et renforcée par l'acceptation du champ littéraire français, grâce aux co-éditions avec Grasset. Les liaisons personnelles avec des autorités des champs éditorial et littéraire ont eu un poids important dans la renommée de ces deux écrivains. Ainsi, Houellebecq put compter sur Dominique Noguez, Philippe Sollers, Fernando Arrabal, Bernard-Henri Lévy, par exemple. Jacques Chessex, de son côté doit aussi son succès à Jacques Mercanton, François Nourissier, Bernard Campiche, Jérôme Garcin ou Bertil Galland, entre autres.

Tous deux partagent pourtant une réputation d'écrivains scandaleux. Afin de comprendre l'origine de leur "politiquement incorrect", observons leur parcours biographique. Leur enfance traumatique, par exemple, a fortement marqué leur écriture. Michel Houellebecq fut éduqué par sa grand-mère; la mauvaise relation avec sa mère Lucie Ceccaldi a débordé aussi bien sur sa fiction ${ }^{3}$, que dans les médias ${ }^{4}$. Houellebecq ne peut qu'avoir honte de sa mère. L'absence de la figure paternelle, elle, se doit à l'insuffisance de contacts du père de Houellebecq avec son fils.

\footnotetext{
${ }^{2}$ Tous deux, il convient de le rappeler, ont commencé leur parcours littéraire en publiant des poèmes. Nous ne retiendrons, dans notre analyse, que la prose des deux écrivains.

${ }^{3}$ Notamment dans Les Particules élémentaires où il en brosse un portrait effarant (Houellebecq, 1998).

${ }^{4}$ II y annonce la mort de sa mère, tandis que celle-ci publie, à grand renfort de publicité, l'accablant $L$ 'Innocente chez Scali, en 2008.
} 
Jacques Chessex, au contraire, fut choyé au sein de sa famille, nonobstant le drame du suicide de son père, qui hantera sa vie et son œuvre. D'autre part, face à sa mère, Chessex avait honte de ses livres immoraux et de sa vie décadente; il ne se sentait pas digne de l'amour qu'elle lui vouait. D'où la résipiscence poignante de son acte de contrition: Pardon mère (Chessex, 2008).

L'éducation de ces deux romanciers a aussi grandement influencé leur parcours. La formation scientifique de Michel Houellebecq laisse des échos dans ses romans dont le style a déjà fait couler beaucoup d'encre. Un prétendu style plat que Michel Houellebecq explique aussi par le souci de "scientificité" de l'écrivain comtien qu'il est, qui ne croit qu'à la preuve de la science dont il adopte ainsi le ton et le discours exact, sans envolée. Une perspective positiviste qu'il n'oublie pas de mettre en évidence dans sa correspondance avec BernardHenri Lévy ${ }^{5}$. II appelle et décrit les choses par leurs noms, sans détours ni fioritures, utilisant, selon l'expression de Rita Schober, un "langage sans fard" (Schober, 2004: 509). Son style plat (discours terne, parfois cru) est pourtant en accord avec sa vision dépressive du monde qu'il décrit de forme sarcastique.

Jacques Chessex, lui, se tourna vers une formation littéraire ${ }^{6}$ qui résonne dans son œuvre: une prose lyrique et baroque, avec des adjectifs parfois rares et une langue intense, des phrases brèves et vives avec très peu de dialogues; des récits mariant le baroque (un mélange d'éclat et de "goût du spectacle de l'anéantissement" (Jaton, 2001: 9)), le gothique, le monstrueux, le bizarre. C'est ainsi que Jacques Chessex se présente, dès l'entrée de son chapitre "Portrait de l'artiste en baroque" dans son autobiographique Carabas: "J'aime ce qui tourne et tournoie, le chahut, le tohu-bohu, la foire pleine d'éclats, l'agglutination, la surcharge, le foisonnement, l'irrégularité et la dissymétrie, l'ornement, le bizarre, les curiosités qui coupent le souffle. J'aime tous les spectacles baroques." (Chessex, 1971: 53).

La composante religieuse est, en effet, un facteur déterminant chez Chessex et c'est surtout son origine calviniste qui dicte le ton de ses histoires. Tous ses personnages se sentent coupables de leur souillure originelle; tous sont dévorés par la faute, le remords, la solitude et la macération du désir. Et c'est en métaphysicien amoureux de la nature qu'il manie avec virtuosité une prose lyrique afin d'exprimer des passions ardentes.

D'autre part, Michel Houellebecq et Jacques Chessex ne cachent pas qu'ils sont redevables aux lectures de leur adolescence: Michel Houellebecq fut, par exemple, marqué par Pascal, Lautréamont, Balzac ou Lovecraft; Jacques Chessex fut un fervent admirateur de La Fontaine, Flaubert ou Maupassant; tous deux s'inclinent devant Aragon ${ }^{7}$. Leur amour

\footnotetext{
${ }^{5}$ Lire, à cet égard, Houellebecq et Lévy, 2008: 150-151).

6 Licence ès lettres à l'Université de Lausanne en 1962, où il y retrouva Jacques Mercanton et y fit la connaissance marquante de Jean Leymarie, professeur français de l'histoire de l'art.

7 "Le plus grand, c'est Aragon avec son matamorisme et ses humeurs et ses injustices et ses coquetteries" (Chessex, 1971: 94), écrit Chessex dans son autobiographique Carabas. Houellebecq évoque le bonheur qu'il
} 
singulier des arts les a aussi poussés à devenir des transécrivains ${ }^{8}$ : Michel Houellebecq se tourne aussi vers la chanson et le cinéma; Jacques Chessex vers le jazz et la peinture.

Plus tard, la vie adulte de nos deux auteurs est marquée par des comportements d'inadaptation sociale. Dépressif, Michel Houellebecq a subi un séjour psychiatrique et se réfugie souvent dans l'alcool et le tabac. Il cultive d'ailleurs cette allure de décalé lors de ses apparitions publiques, retournant se blottir très vite dans son repère en Irlande. Car cet écrivain fuit la France pour plusieurs raisons: procès judiciaires, menaces de mort, politique fiscale défavorable, etc. Par contre, il ne cache pas son désir de reconnaissance venant de l'Hexagone, tout comme sa mégalomanie, tel qu'il le prouve dans sa réaction d'arrogante vanité lorsqu'il reçut le Prix Interallié en $2005^{9}$ ou chaque fois qu'il ratait le Prix Goncourt ${ }^{10}$ (alors que lauréat cette année, il s'est déclaré "profondément heureux" de cette récompense, sans oublier de remercier François Nourissier, son plus ancien et fervent défenseur). Jacques Chessex, au contraire, a plutôt joué sur l'humilité, même lorsque, en 1973, la remise de son Prix Goncourt fut accusée d'être le résultat de manigances éditoriales.

Cependant, Jacques Chessex a longtemps vécu tourmenté par ses fantômes qui l'ont fait se perdre dans l'alcool, les femmes et des rixes violentes dans les cafés. Jusqu'au 31 décembre 1987, où il fit le serment de se "désencombrer", comme il aimait à le dire, de ces vices.

D'autre part, alors que Michel Houellebecq n'a aucun mal à abandonner son pays d'origine, la France, pour se fixer à l'étranger, Chessex n'a jamais voulu quitter sa Suisse natale, restant toujours fidèle à son pays vaudois. Nonobstant, il a toujours défendu l'idée d'être publié à Paris, mais sans y voir la nécessité de s'y installer. Il se comparait lui-même à la chouette effraie, parce qu'elle vit dans l'ombre des clochers, des hauts arbres solitaires, et parce qu'elle a la sagesse de ne jamais s'épuiser à changer de territoire: "C'est un oiseau discret, il vit dans l'ombre, il regarde dans l'ombre: leçon pour un écrivain. [...] L'effraie est

\footnotetext{
prit à faire l'éloge d'Aragon dans Ennemis Publics (Houellebecq et Lévy, 2008), un exercice d'admiration auquel il aime à se livrer et qui lui manque, avoue-t-il, lors de l'émission radio "Le 7/10", présentée par de Nicolas Demorand, diffusée sur France Inter le 10 octobre 2008 (cf. http://www.dailymotion.com/video/x70uqy_mhouellebecq-et-b-h-levy_news).

${ }^{8}$ Nous empruntons l'expression de Jean-François Patricola (Patricola, 2005: 88).

${ }^{9}$ Quelques instants après avoir reçu ce prix, il déclare aux journalistes: "Je suis bien là, je suis plutôt content. C'est normal que j'aie eu un prix, d'une manière ou d'une autre, sinon il y aurait une espèce d'illogisme qui serait choquant". Non parce qu'il trouve son roman le meilleur, mais parce qu'il se considère comme la marque d'un tournant dans l'histoire littéraire: "je dois représenter quelque chose, une mutation quelconque" (cf. http://www.ina.fr/art-et-culture/litterature/video/2960048001031/prix-interallie-houellebecq.fr.html).

${ }_{10}$ Dominique Noguez décrit d'ailleurs comment Houellebecq fut vraiment affecté en 1998 (cette année-là, le prix Goncourt fut décerné à Paule Constant pour son roman Confidence pour confidence), se réfugiant dans l'alcool (cf. Noguez, 2003: 89-91). Sachant que son roman Les Particules élémentaires fut écarté des finalistes, il s'écrit d'ailleurs: "Ce sera un jour de deuil pour la littérature!" (apud Noguez, 2003: 88). II affirma aussi, lors d'un entretien avec Antoine de Gaudemar, paru le 19 novembre 1998 dans Libération: "[le livre de Paule Constant] est médiocre, pas antipathique mais raté". Quant aux jurés du Prix Goncourt, il les accuse d'être vendus: "mon éditeur [Flammarion] n'avait pas de ligne budgétaire pour acheter les jurés!". De même, quand son roman La Possibilité d'une île fut devancé d'une seule voix par Trois jours chez ma mère de François Weyergans en 2005, malgré l'appui de Nourissier, Houellebecq, mauvais perdant, assena "Le système des prix est tellement opaque qu'il vaut mieux ne rien en attendre".
} 
une apparition, un cadeau mobile de la nuit. Elle n'éclaire pas. Elle a sa propre lumière [...]. L'effraie n'émigre pas, ne change pas de territoire" (Chessex, 2005: 292-295). Dans son Carabas, Chessex avouera sa difficulté à sortir de son pays:

Il y a surtout la racine: difficilement arrachable. Enracinement, 'retour au pays natal' [...]. II ne s'agit d'aucune mystique paysanne [...]. Simplement, [...] j'ai besoin de ce pays comme Baudelaire avait besoin de Paris. Je déteste en sortir parce que je perds ma foule et mes paysages. (Chessex, 1971: 116).

Le pays vaudois ne lui a tout de même pas encore pardonné d'avoir vendu ses archives personnelles aux Archives littéraires suisses à Berne en 1996: une trahison jugée politiquement incorrecte.

Néanmoins, comme l'a souligné Gérald Froidevaux, Jacques Chessex "a [...] apporté une contribution notable à la défense et à l'illustration de la littérature romande" (Froidevaux, 1998: 406). En effet, il multiplia les initiatives de promotion de la littérature vaudoise comme les revues Pays du Lac (1953-1955) ou Ecriture (1964), la fondation des prix littéraires George Nicole et Edouard Rod, mais aussi dans des essais comme Les Saintes Écritures (1972) ou une "belle hagiographie vaudoise et romande" dans son Carabas (Chessex, 1971: 204-205). A titre de comparaison, Michel Houellebecq, auteur de textes tels que "Jacques Prévert est un con" ${ }^{11}$ (Houellebecq, 1997: 67ss), cherche encore son autorité dans le monde des lettres. II regrette, d'ailleurs, le fait de manquer d'influence auprès de son éditeur afin de faire publier des nouvelles d'une lectrice qui réclamèrent son attention.

\section{Politiquement incorrects}

Michel Houellebecq et Jacques Chessex ont cultivé une posture médiatique sui generis. Les prestations télévisuelles du premier donnent l'effet de mises en scène programmées: un aspect simplet qui jure sur le caractère prétentieux de l'auteur; des réponses laconiques et titubées ou des propos frisant le scandaleux, qui rehaussent le ton virulent de son écriture; une voix monotone et sourde, interrompue par des pauses sempiternelles. Un balbutiement qui pourrait pourtant être rapproché du ton dépressif de sa fiction, de ses doutes et inquiétudes. La seule fois où Michel Houellebecq parle avec fluidité, c'est lors de ses lectures publiques, où l'abstraction de la pensée et de la réflexion laisse courir son discours sans obstacles.

Houellebecq est aussi connu pour sa relation malsaine avec les médias. Tantôt peuvent-ils aider à sa promotion, tantôt diffusent-ils ses scandales comme la rupture avec la

\footnotetext{
${ }^{11}$ Cet article est d'abord paru le 22 juillet 1992 dans Lettres françaises.
} 
revue Perpendiculaire, la fameuse "affaire Houellebecq" de 2001, où l'auteur fut mené en justice par des associations musulmanes. C'est aussi par l'intermédiaire des médias que Houellebecq échange des piques avec Michel Onfray, Denis Demonpion ou Daniel Lindenberg. Mais, à bien y voir, le discours médiatique actuel ne revendique-t-il pas, surtout en France, le politiquement incorrect, générateur d'audience, avec les agitateurs du Paf ${ }^{12}$ qui utilisent à dessein - indécent - la raillerie?

Jacques Chessex a eu, lui aussi, une posture médiatique contrastée: avant et après ses excès alcooliques. II suffit de voir ces deux prestations afin de noter la différence: l'émission "Livre à vous" sur TSR du 8 février 1987, présentée par Yves Lassueur, à propos de la parution de Jonas, où Jacques Chessex se présente très visiblement ivre et l'émission "Dans quelle étagère" du 12 février 2008, sur Fr2, présentée par Monique Atlan, à propos de l'édition de Pardon mère. Une interview chargée de sincérité et d'émotion, où chaque mot de Chessex, plus serein, est pesé. L'authenticité de son émoi face au repentir de ne pas avoir été digne de l'amour de sa mère est déchirante.

Pourtant, même ivre, Chessex a toujours eu un discours recherché, un débit mélodieux et une voix caressante qui ont inspiré du respect. II a d'ailleurs sans cesse travaillé sa télégénie d'écrivain baroque. Ses prestations médiatiques étaient accompagnées par "ses gestes grandiloquents, ses expressions plutôt dramatiques et son discours aux accents bibliques [qui] n'ont jamais laissé indifférents les médias." 13

Quant à sa relation avec ceux-ci, même si moins fréquente que celle de Houellebecq, elle s'est tout de même développée, aussi, hors-frontières; ce qui est digne d'être souligné pour un écrivain né dans un pays où la discrétion est une valeur morale.

Cependant, le côté suisse de Jacques Chessex en a fait un écrivain peu porté à s'attarder sur les mondanités et il tourna donc le dos à la médiatisation. L'auteur le confessa lui-même: "Je me méfie des évidences, de ce qui est donné sans discussions, de ce qui est trop vite lumière, des écrivains illustres: cela veut dire qu'ils sont trop clairs." (apud Armel, 2007: 93). Néanmoins, travailler avec les médias ne lui a jamais répudié. En effet, il a prêté sa collaboration à des journaux et des revues suisses ou hors-frontières ${ }^{14}$. Cependant, à l'inverse de Michel Houellebecq qui intervient aussi bien dans des médias dits sérieux que dans la presse people, Jacques Chessex, de son côté, a choisi de se confier uniquement aux médias à tendance littéraire.

Ceux-ci ont, bien-sûr, contribué à la diffusion internationale de cet auteur. Ils ont aussi aidé à envenimer les polémiques de Chessex, que ce soit à propos du contenu

\footnotetext{
${ }^{12}$ Paf (Paysage Audiovisuel Français), nous le rappelons, est une expression familière pour désigner l'aspect général, la diversité qualitative, des programmes de la télévision et de la radio françaises.

${ }^{13}$ Une posture ainsi résumée par une internaute (posté le 21 mars 2009 par Palmonlive dans l'espace consacré aux réactions à un article de Michel Danthe (Danthe, 2009)).

${ }_{14}$ Lire, à ce propos, les références bibliographiques présentées par Marius Michaud (In Froidevaux et Michaud, 2003: 155ss).
} 
dérangeant de ses œuvres, ou des relations parfois explosives avec des pairs, comme Charles-Edouard Racine dont l'essai L'imposture ou la Fausse Monnaie (Racine, 1997), critique sévère de la valeur littéraire de Chessex, poussa l'écrivain suisse à répondre avec la publication du pamphlet Avez-vous déjà giflé un rat ${ }^{15}$ (Chessex, 1997) ${ }^{16}$.

Rappelons aussi la polémique engendrée avec Henri Guillemin et son émission télévisée controverse "A la découverte de la littérature française". Contre cet historien, Jacques Chessex écrit "Je voudrais signaler à M. Guillemin" dans son Carabas (Chessex, 1971: 71-74) ${ }^{17}$, dont l'enjeu est de "signaler à M. Guillemin quelques-uns des traits les plus répugnants de [son] caractère" (Chessex, 1971: 71). Chessex dresse l'auto-portrait de ses "saletés": son "ignoble goût de la duplicité et du mensonge", son "faible pour les distinctions" (Chessex, 1971: 72-73). II ajoute: "Faux jeton, putain, rusé, vicieux, me voici Monsieur le décrypteur." (Chessex, 1971: 72). Puis, en vers, "gourmand, / paresseux, / vite distrait, / badaud et même curieux des autres, / capricieux, / désinvolte, / pas prêteur, / oublieux du bien qu'on me fait, / mufle par insouciance, / précipité, / calculateur, / dissimulateur, / violent." (Chessex, 1971: 73).

Un portrait qu'il récapitulera dans le chapitre "La septième trompette de Jéricho":

C'est un écrivain qui souffle dans sa trompette dérisoire. Un écrivain maniaque, d'ailleurs il est méchant, il vous l'a dit, il est pochard, il est retors, il est menteur, il est gourmand, il est coureur, il est bavard, et blasphémateur, fornicateur, comédien, paresseux, sédentaire, rôdeur, putain, velléitaire, faux comme la lune, vaniteux, voleur, il vous l'a dit, il vous l'a dit, il vous l'a dit. (Chessex, 1971: 250).

Le ton est vif, violent, parodique, conformément à la personnalité de Chessex. Qui plus est, Guillemin est en butte aux quolibets de Chessex qui l'appelle "le fouilleur", "le médisant", le "corbeau", et qui lui prête des jugements trop puritains sur les écrivains qui ont participé aux Cahiers de la Renaissance vaudoise:

\footnotetext{
${ }^{15}$ Par la même occasion, dans son pamphlet Avez-vous déjà giflé un rat, Jacques Chessex répondait à Jérôme Meizoz qui accusait l'existence d'un "complot" qui lui permettait d'avoir du succès: "maître Bourdieu définit la littérature francophone comme le perpétuel rapport de force du dominé (la province) et du dominant (Paris), qui expliquerait, ipso facto, la situation des lettres romandes. Cette vision relève de la haine de la littérature. Elle méprise et nie la qualité intrinsèque de l'écrivain, son origine, sa nature, ses ascendants religieux, moraux, etc. Elle est elle-même sociologiquement fausse, puisqu'elle suppose tous les écrivains tributaires d'un même lieu: or C.F. Ramuz n'est pas romand, il est Vaudois. [...] Jacques Chessex n'est pas romand, il est Vaudois, il a publié ses romans à Paris, et ses livres de poésie en Suisse. [...] Est-ce le complot, Monsieur Meizoz? Ou daignerezvous autoriser Jacques Chessex, qui avait vingt-cinq ans dans les années soixante, à publier dans la N.R.F. de Paulhan et d'Arland, à se lier avec Nourissier, [...] Jérôme Garcin... et les écrivains du jury Médicis, dont il fait partie, au lieu de couiner dans une revue de La Chaux-de-Fonds ou de s'engluer dans les colonnes du 'Samedi littéraire'." (Chessex, 1997: 82).

${ }^{16}$ II s'y attaque aussi à Jacques-Etienne Bovard, Jérôme Meizoz ou Jean-Louis Kuffer. C'est d'ailleurs avec cet autre écrivain que Jacques Chessex entretint une liaison professionnelle politiquement incorrecte, oscillant entre l'attaque et la louange.

${ }^{17}$ Les deux se sont pourtant retrouvés lors de l'émission littéraire Noir sur Blanc, diffusée sur TSR, le 4 mai 1981.
} 
Ah une jolie maffia, cette Renaissance. [...] Un ramassis d'obsédés sexuels, de violents malins, de porc habiles à faire monter leurs tirages en corsant leurs torchons d'érotisme faisandé et de bassesse. Là-dessus souffle leur dompteur, [...] leur âme damnée, le matois éditeur Galland [...]. Pouah. Où est la dignité? La saine réserve? La décence? (Chessex, 1971: 72).

L'exercice burlesque se termine en apothéose: "J'ose à peine rester en vie tellement je désire que mes restes provoquent l'ire de M. Guillemin. Je vivrai pourtant, persévérant dans la boue noire [...]. Je me console comme je peux: jeux de Guillemin, jeux de vilain... O raisins verts" (Chessex, 1971: 74). Chessex, nourri aux fables de La Fontaine par sa mère, faisait certainement allusion à la fable "Le renard et les raisins", inspirée de l'apologue de Phèdre - que Chessex a souvent cité -, lequel est précédé par cette maxime: "le glorieux (Guillemin?) méprise ce qu'il ne peut avoir" ${ }^{18}$.

Enfin, encore à propos des tapages médiatiques de Jacques Chessex, nous pourrions aussi pointer la fustigation de l'écrivain suisse romand en 1991, dans Le Nouveau Quotidien contre la célébration à Carouge de l'écrivain René-Louis Piachaud, fidèle collaborateur du Pilori, périodique fasciste.

Quant à la réception de l'œuvre, à la différence de Chessex, Michel Houellebecq est loin de recueillir un large consensus ${ }^{19}$. Pas de concordance d'opinion sur son œuvre entre le lecteur commun et la critique universitaire ${ }^{20}$, par exemple. De même, il semble que Houellebecq soit mieux reçu hors-frontières ${ }^{21}$ que dans son propre pays.

Les livres chessexiens, sans que leur valeur littéraire ne soit mise en cause, ont toujours déclenché beaucoup de réprobation, voire même de censure en Suisse; une réception bien différente du marché français. Alors que dans l'Hexagone, la publication de son Un juif pour l'exemple (Chessex, 2009) remporta un franc succès, en Suisse, le roman

\footnotetext{
${ }^{18}$ Par coïncidence (ou non), Les Raisins verts était une émission télévisée de variétés créée en France, en 1963, qui déclencha beaucoup de polémique à cause de son humour noir.

19 Une association "Amis de Michel Houellebecq" s'est formée sur le web (http://wwww.membres.lycos.fr/houellebecq/fr/accueil290801.html, page web consultée le 25/03/2000), créée par Michelle Lévy, celle-ci étant critiquée pour son travail censorial et pour son but marketing par l' "Amicale des ennemis des Amis de Michel Houellebecq" (http://aeamh.free.fr/, page web consultée le 25/03/2000), créée par Frédéric Vignale.

20 Selon des analystes et des critiques comme Eric Naulleau, Houellebecq est un auteur "qui possède une surface médiatique [...] considérable", mais sans aucune étude critique dite sérieuse (Naulleau, 2005: 61). Naulleau explique alors, en partie, le succès de Michel Houellebecq, par "le peu d'intérêt que lui manifeste la critique littéraire [...] ([distincte] du journalisme littéraire) et par la franche indifférence de l'université à son endroit”. (Naulleau, 2005: 62).

${ }^{21}$ On peut trouver, par exemple, des articles de presse élogieux venant de plusieurs zones du monde, comme le Brésil, l'Argentine, les Etats-Unis, l'Angleterre, les Pays-Bas, le Danemark, l'Allemagne, l'Espagne, le Portugal, I'Italie, Israël, Moscou, etc. Voir, par exemple, le film d'Asya Nemchenok -VIDEOPOESIA project - sur http://www.actualite-de-stars.com/videos/michel-houellebecq/michel-houellebecq-un-autre-vieparis.html ou une interview de Houellebecq à Varsovie en 2008 sur http://www.actualite-de-stars.com/videos/michelhouellebecq/michel-houellebecq-interview-in-warsaw.html.
} 
fut suivi d'un tonnerre de condamnations ${ }^{22}$, à commencer par celles du maire et de l'archiviste de Payerne, qui préféraient que le souvenir de ce crime nazi dormît en paix. Car, ce qui dérangea, c'est que l'auteur ait déterré cette histoire véridique et qu'il ait osé affirmer que tout le monde savait, à l'époque, ce qui se tramait: "On se couperait la langue, on se crèverait les yeux et les oreilles plutôt que de reconnaître que l'on sait ce qui se trame au garage. Et dans les arrière-salles de certains cafés. Et dans les bois. Et chez le pasteur Lugrin." (Chessex, 2009: 30). Mais entre dénoncer un crime et le taire, qu'est-ce qui est le plus politiquement incorrect? Où se situe l'infamie?

Pour faire payer son audace, Jacques Chessex a déclaré avoir reçu des menaces de mort. Au Carnaval de Payerne 2009, on put voir un char figurant une boille ensanglantée, un os, et le nom de "Chessex" écrit avec les deux "S" du symbole des SS nazis.

Autre exemple plus récent, le roman posthume de Chessex, Le dernier crâne de $M$. de Sade (Chessex, 2009b), est mis en vente en Suisse sous cellophane avec un macaron "réservé aux adultes". En France, rien de ce genre; d'ailleurs, en comparaison, le polémique Plateforme de Houellebecq, aux descriptions pornographiques plus scandaleuses, est un roman à la portée de tous. II existe même en édition de poche. La crudité des romans houellebecquiens, si elle choque, n'est pas censurée. Dans la Suisse calviniste, où le corps est pris comme temple de Dieu, l'érotisme est déjà une faute, tout comme l'écriture du corps, quel que soit le langage utilisé...

La présence du corps dans les romans de ces deux auteurs est pourtant symptomatique dans la littérature du tournant du XXème siècle. En effet, selon Claude Burgelin, bien des textes de l'actualité littéraire "reviennent de façon lancinante sur l'incarnation et les modes de présence du corps. Ils mettent au premier plan de la scène, souvent avec violence ou âpreté, l'organique, le charnel, le sexuel." (Burgelin, 2003: 48). II s'agit d'une écriture qui se délivre de toute métaphore, qui opte pour un discours plus cru, livrant le corps à sa nudité dans l'euphorie de l'immédiat. D'où "peu de syntaxe, peu de circonstancielles, des parataxes, un présent de l'indicatif omniprésent, des phrases brèves ou, au contraire, sans coupes ni arrêts, une rythmique de l'intensité." (Ibidem).

Cependant, chez Houellebecq, ceux qui ne peuvent accomplir l'échange corporel sont voués à l'isolement et à la solitude, satirisés dans ses fictions narratives. Selon la formule de Liesbeth Althes, dans l'univers houellebecquien, "derrière la faim physique, c'est le vide spirituel qui creuse." (Althes, 2004: 33). Certes, nos deux romanciers ont tous deux

\footnotetext{
${ }^{22}$ Jacques Chessex avait aussi proposé à la ville de Payerne de rendre hommage à Arthur Bloch en rebaptisant la place de la Foire en place Arthur-Bloch, et en scellant une plaque dans la Rue-à-Thomas, où eut lieu le crime. Sa proposition fut rejetée. Pour faire suite à l'affaire, les autorités communales décidèrent de nommer une commission extraparlementaire chargée de rédiger une résolution qui parut quelques mois plus tard. Le texte de cette résolution insiste sur la nécessité d'un travail de mémoire: "Même s'il peut être douloureux, ce rappel du passé doit conduire aujourd'hui à un travail de prévention et d'engagement contre toute forme de racisme et de discrimination". De plus, la résolution rejette toute condamnation collective de la population de Payerne de 1942 ou de 2009.
} 
choisi des personnages en quête d'assouvissement. Mais, chez Chessex, en dépit du remords calviniste, le sexe est une recherche épanouie de l'absolu.

D’une façon générale, l'œuvre de Michel Houellebecq choque surtout par la perspective adoptée par l'auteur sur la contemporanéité et son interprétation sociologique de la "moyenneté": ses personnages sont représentants de ces classes moyennes-élevées dépressives de la société occidentale, en milieu de vie (cf. Houellebecq, 2010: 98).

De son côté, les romans de Jacques Chessex sont habités par des pasteurs dévoyés, des notables en perdition et des amants que foudroie le sentiment protestant de la faute. Des personnages qui circulent entre une nature primitive et préservée, des lieux de prière, des habitations campagnardes, auxquels viennent se joindre, en opposition, des cafés, des bars, des maisons de tolérance où se développe l'industrie du plaisir. L'alcool est un vice qui mine la plupart des héros chessexiens, alter ego de l'auteur qui confessa "Dans le vin, dans le vin surtout, je n'ai jamais cherché qu'à m'enfoncer en moi-même, à m'habituer mieux, à coller de plus près à mes os." (Chessex, 1971: 21-22).

Jacques Chessex mélange aussi le sacré et l'érotisme, ce qui fait que beaucoup crient au sacrilège. II marie la beauté naturelle de la Suisse ${ }^{23}$, la surface calme des lacs suisses aux turbulences de ses eaux troubles, c'est-à-dire aux actes immondes et dissimulés de ses habitants, véritables effluents du lisier que sont les mœurs immorales décrites dans ses romans. Pour cet écrivain, dans son pays, "le pire côtoie la paix absolue" ${ }^{24}$. Ses romans révèlent les dessous d'une Suisse à l'image calviniste, bien-pensante. Car l'auteur de Un Juif pour l'exemple est surtout un dénonciateur, bien plus qu'un simple provocateur.

C'est, comme il l'écrivit, un écrivain "qui pousse l'air de sa petite poitrine dans sa trompinette à la noix. [...]. Mais qu'est-ce qu'un livre? Je voudrais que le mien soit la septième trompette, la septième trompette de Jéricho." (Chessex, 1971: 250). Et comme Chessex le rappela maintes fois, ses détracteurs l'accusaient de "peindre le diable sur la muraille"25, expression suisse qui signifie noircir la situation, évoquer des dangers imaginaires. Dans son roman Le vampire de Ropraz, Jacques Chessex glisse ce commentaire "Dans ces déserts, le symptôme du vampire durera tant que cette société sera victime de la crasse primitive: saleté des corps, promiscuité, isolement, alcool, inceste et superstitions qui infestent ces campagnes..." (Chessex, 2007: 73). En poète, l'écrivain chantonnait dans son Carabas "on n'écrit pas de bouquin sans casser des œufs. Ça cogne et rogne, ça charogne, l'ivrogne besogne ses vergognes, ça grogne de Payerne à Rarogne." (Chessex, 1971: 207). Ou encore: "En moi la folie calviniste et les vertiges de la

\footnotetext{
${ }^{23}$ Chessex décrit très bien la sublimité de la nature suisse, contrairement à Houellebecq, qui n'a jamais éprouvé d'intérêt pour la nature et qui multiplie ses invectives contre les écologistes.

${ }_{24}$ Cf. l'émission religieuse "Racines" du 27 mai 1990, présentée par Jean-Pierre Moulin. (http://archives.tsr.ch/dossier-chessex/personnalite-chessex1).

25 Lire, par exemple, Chessex, 1971: 253.
} 
transgression. [...] Je suis né de la colère et du remords" (Chessex, 1971: 223, 225). Chessex, le citoyen auteur, le dit lui-même ${ }^{26}$ :

Le calvinisme, il est dans ma chair, il est dans mes os, jusqu'à la fin. [...] Le vaudois est quelqu'un qui est dévoré de remords et macéré dans la solitude. Ce qui lui manque, tout comme dans la littérature vaudoise est qu'elle ne se dit pas assez, elle ne se confie pas assez. Et moi, je suis dans l'aveu [et] j'aime bien percer les cœurs. ${ }^{27}$

Lors de sa participation aux Journées des Écrivains du Sud ${ }^{28}$ en mars 2009, le romancier insiste: "J'aime l'échec, hésiter, raturer. J'aime cultiver la chute, la rechute, l'enfermement" (apud Garcia, 2009). Et pourtant, il faut le rappeler, Jacques Chessex est aussi l'auteur de quatre ouvrages pour enfants!

Se rebellant contre le conformisme ambiant et toute contrainte, dérangeant, il privilégie le mal et la perversion dans son œuvre. Surtout la dépravation sexuelle... N'écrit-il pas une espèce d'ode à la menstruation dans son effroyable Carabas (Chessex, 1971: 55)? Ne parle-t-il pas avec délectation de la masturbation féminine (Chessex, 1971: 125-126)? Les femmes chessexiennes sont immorales, souvent mêlées à des pratiques sexuelles dépravées, où la bestialité de l'homme est mise à nu. À l'obsession houellebecquienne pour les fellations, Jacques Chessex oppose ses "odes au cunnilingus" (Garcin, 2003: 48).

Par ailleurs, le fait que Chessex s'inspire de crimes réels de son pays ajoute au scandale. Ainsi, l'histoire de Judas, le transparent, publiée chez Grasset, en 1982, a pour origine une histoire vraie de la secte des Contemplateurs de l'Arche de Noé dont le pasteur Stocker a assassiné une de ses jeunes fidèles avec un fouet. Le vampire de Ropraz (Chessex, 2007) et Un juif pour l'exemple (Chessex, 2009) sont d'autres récits ayant pour origine une histoire vraie.

L'écriture chessexienne est, en effet, embarrassante pour ses compatriotes: comment ne pas s'offusquer de leur description cinglante dans son Portrait des Vaudois (Chessex, 1969)? De l'insistance chez Chessex à exposer leur hypocrisie, leur calvinisme

\footnotetext{
${ }^{26}$ Pour le Dictionnaire des écrivains contemporains de langue française par eux-mêmes, publié par Jérôme Garcin, il avait rédigé, non sans humour, sa propre notice biographique en 1988: "Depuis 1969, il est professeur au Gymnase de la Cité, à Lausanne, où son indépendance d'esprit - refus des modes et des conventions, détestation des Trissotins, méfiance des accommodements officiels, dérision des veuleries provinciales - lui donne une stature singulière qu'augmente évidemment l'audience de ses livres à Paris, dans la francophonie et dans le monde entier: Chessex est traduit dans une quinzaine de langues." (Chessex, 1988).

${ }^{27}$ Émission du 20 septembre 2009 "Vu à la télé", présenté par Pascal Rebetez: (cf. http://archives.tsr.ch/dossierchessex/emissiontele-200909).

${ }^{28}$ Colloque où participa aussi Amélie Nothomb qui devait rejoindre Chessex en décembre 2009 pour une "rencontre improbable" organisée par la Société de Lecture de Genève. La mort de l'écrivain suisse a rendu impossible ce rendez-vous. Interviewée, la romancière témoigne de la considération réciproque entre les deux et de sa gêne à la lecture de Chessex, "comme quand on lit quelque chose qu'on ne doit pas lire et qui fascine" (cf. http://www.letemps.ch/Page/Uuid/f2fdf3d0-de9f-11de-801c-518ea5779929).
} 
aigu? De les comparer maintes fois au $\operatorname{cochon}^{29}$, base de leur alimentation qui semble avoir déteint sur eux? De parler de débauche dans un pays qui affiche l'image d'une morale ascétique? Son premier récit La tête ouverte, publié en 1962, chez L'Âge d'Homme, mettait déjà face à face la vie de bohème du narrateur et l'homosexualité de deux colocataires masculins, au sein d'une moralité bon chic bon genre défendue par ceux qui les entourent et qui les condamnent.

Ses personnages ne sont-ils pas, comme le lui a fait remarquer Bernard Pivot, de "vieux cochons"? Ne décrit-il pas "les cochonneries" de Sade dont il vient même à placer le crâne dans les coffres suisses ${ }^{30}$ ? Le vampire de Ropraz, au lieu d'être décrit comme un criminel épouvantable, bénéficie de références à une enfance d'abus sexuels. Pour comble d'ironie, Chessex l'ennoblit dans une mort hérö̈que, au service de la Légion: il serait même le soldat inconnu enterré sous l'Arc de Triomphe ${ }^{31}$ !

Mais, pire encore, Chessex mélange Dieu et le sexe. De telle façon que ses détracteurs se complaisent à appuyer sur son x patronymique (Chessex). En effet, l'auteur le répète souvent: c'est dans le corps, dans le sexe de la femme - qu'il préfère toucher, humer, goûter plutôt que de simplement pénétrer - que l'on peut retrouver Dieu ${ }^{32}$. Un Dieu qui lui apparait comme un éblouissement, alors qu'il est submergé par le pire, lorsque l'excès d'horreur le précipite dans l'absolu, comme après avoir siroté de l'urine d'une institutrice (épisode narré dans "Dieu, la mort" de Carabas (Chessex, 1971: 209-217), après avoir plongé à moto, ivre, dans le lac Léman, après avoir jeté la bague de fiançailles de son père dans une bouche d'égouts, après avoir cogné l'évêque de Lausanne et Fribourg... Bref, comme le résume Chessex, "ainsi dans chaque agonie. Dans l'abomination et la souillure. Et sans remords. Sans tristesse. [...] Comme une ascèse [...], et je vois Dieu, je comprends, j'aime, je cède." (Chessex, 1971: 213).

Ce qui me fascine [...], c'est que à l'intérieur de la chair des femmes, [...] il y a le sacré, il y a la maternité, il y a l'empire, il y a le royaume, la douceur, la tendresse [...], une espèce de pouvoir à la fois rituel [...], sacré et puis la mort [...]. A travers cette chair, il y a quoi? II y a Dieu!

explique Chessex à la journaliste Catherine Charbon lors de l'émission "La voix au chapitre" du 11 août $1975^{33}$, dédiée à son roman L'ardent royaume (Chessex, 1975).

\footnotetext{
${ }^{29}$ En guise d'exemples, lire Chessex, 1969: 27 ou Chessex, 2009. Les Vaudois sont aussi assimilés au veau (cf. Chessex, 1969: 25).

${ }^{30}$ Cf. Chessex, 2009b.

${ }^{31}$ Cf. Chessex, 2007.

${ }^{32} \mathrm{La}$ figure de la femme dans l'œuvre chessexienne est riche en interprétations et symbolismes. On espère qu'une étude sur la représentation de la femme chez Chessex pourra bientôt voir le jour...

${ }^{33} \mathrm{Cf}$. http://archives.tsr.ch/dossier-chessex/personnalite-chessex3.
} 
Et c'est encore ici que Michel Houellebecq le rejoint. Dans son roman Plateforme, on peut lire: "À quoi comparer Dieu? D’abord, évidemment, à la chatte des femmes" (Houellebecq, 2001: 157ss). Mais alors que Houellebecq pousse à l'excès dans Les Particules élémentaires avec le personnage Bruno qui se masturbe en voyant la vulve de sa mère, Jacques Chessex avoue dans une interview: "La figure de ma mère et de ma sœur, [...] ces deux images n'ont jamais été mêlées pour moi [...] à des fantasmes ou des représentations d'ordre sexuel. Jamais." (apud Bridel, 2002: 70) ${ }^{34}$.

Échos du malaise de notre époque, l'œuvre de Chessex et de Houellebecq est traversée par la solitude et le néant, issus, surtout, de la non-présence active de Dieu et de l'adversité qu'est la mort. D'où l'inclusion du suicide et de l'euthanasie dans leur fiction ${ }^{35}$. La fatalité qui accompagne leur vision du monde est encore plus tragique, puisqu'elle est irréversible. La différence est que l'on ne rit pas avec les romans chessexiens.

Pourtant l'auteur dit aimer rire dans la vie, comme il l'écrit dans son chapitre "Les gorges chaudes" de son autobiographique Carabas (Chessex, 1971: 47-51). Mais le rire est socialement condamné dans les cantons suisses calvinistes, comme Chessex l'évoque ironiquement:

- Quoi, vous disiez qu'à Lausanne on ne rit pas bien? - Je connais des gens pour qui rire est tout au plus un toussotement exténué. Un chuintement distingué. [...] Allez rire dans cette société, vous passerez vite pour un Scythe. Vous riez sans retenue? Vous éclatez de rire? Vous êtes gai, votre tablée se tord les côtes? Vous voilà fiché, étiqueté. Coureur, bretteur, on savait, mais aussi grossier, c'est bien pire. (Chessex, 1971: 48).

Dans sa fiction, du moins, Chessex étouffe son rire et l'ennui, la cruauté, l'érotisme sont, à bien y voir, caricaturalement décadents dans ses récits.

La fiction houellebecquienne est, au contraire, pleine d'un humour grinçant ou de cet humour noir que les plus puritains jugeront politiquement incorrect et auquel contribuent, par exemple, le contraste et le commentaire déplacé.

Les exemples abondent, surtout lorsqu'il est question d'un décès. Lors de la cérémonie de crémation du personnage Di Meola de Les particules élémentaires, l'héroïne Christiane raconte, dans un passage très comique:

\footnotetext{
${ }^{34}$ Une remarque plusieurs fois répétée dans Pardon mère (Chessex, 2008). II faut tout de même rappeler qu'il est parfois dangereux de mêler réalités vécues et fictionnelles. Avec ces deux auteurs, l'ambiguïté auteur/narrateur/personnages rend trouble et difficile la séparation des deux.

35 Jacques Chessex a aussi parlé de la mort, en 1963, à Noël, de sa première fille encore fœtus de cinq mois dans son Carabas (Chessex, 1971) qu'il appelle, néanmoins "son enfant" en parlant de son épouse Michèle, dévastée physiquement et psychologiquement par la fausse couche. Lire, par exemple, le chapitre "Césarienne" (Chessex, 1971: 121-123), où il se dit coupable d'avoir "abîmé" sa femme tout en sachant qu'il allait la quitter et où la certitude d'avoir "tué un enfant" l'étouffe.
} 
Pour réaliser une crémation, en principe, il faut de l'encens et du santal. Là on avait juste ramassé des branches tombées, probablement mélangées avec des herbes locales - du thym, du romarin, de la sarriette; si bien qu'au bout d'une demi-heure l'odeur s'est mise à évoquer exactement celle d'un barbecue. (Houellebecq, 1998: 253)

Chez Houellebecq, une situation vague ou solennelle est souvent interrompue par la réalité crue et imminente, sans changement de paragraphe. Fréquemment, deux situations inassimilables sont amplifiées par l'utilisation du point-virgule. Ainsi, après avoir décrit le coït de ses parents qui donna lieu à sa conception, le narrateur d'Extension du domaine de la lutte conclut: "Elle avait éprouvé du plaisir, mais pas de véritable orgasme. Peu après, ils avaient mangé du poulet froid. II y avait de cela trente-deux ans, maintenant; à l'époque, on trouvait encore de vrais poulets." (Houellebecq, 1994: 174). Dans Plateforme, le narrateur travaille avec Jean-Yves et Valérie sur le projet des clubs touristiques Aphrodite; s'ensuit ce paragraphe, sans interruption afin de souligner la simultanéité et l'inconscience des deux actions: "Nous fîmes une pause rapide pour aller déjeuner. Au même moment, à moins d'un kilomètre, deux adolescents [...] éclataient la tête d'une sexagénaire à cous de battes et de baseball. En entrée, je pris des maquereaux au vin blanc." (Houellebecq, 2001: 247).

Néanmoins, cette insertion incommode de phrases qui viennent buter contre ce qui vient d'être dit peut nous rappeler le zapping télévisé. Ou une parodie des journaux télévisés (comme l'ont déjà fait, dans un autre registre, Coluche, Pierre Desproges ou Les Guignols de l'Info, par exemple) qui font s'ensuivre de mauvaises nouvelles entrecoupées de choses anodines ou heureuses, sous la posture impassible, le flegme, voire la froideur, du journaliste-pivot. S'agit-il, pour Houellebecq, de démontrer ainsi l'indifférence de l'humanité face au malheur d'autrui? S'agit-il de pointer la banalisation du malheur et de l'horreur, dont les médias sont les principaux fomentateurs coupables? Ou bien, tout simplement, le but estil d'illustrer la solitude et l'abîme issus de l'individualisme provoqué par mai 68? De montrer que toute mutation, pour Houellebecq, est irréversible? Toutes ces hypothèses partagent le fait qu'elles sont politiquement incorrectes.

Michel Houellebecq s'attaque, en effet, à des thèmes qui dérangent: la solitude existentielle - la description du contemporain dépressif est son image de marque -, la pornographie, l'anti-islamisme, l'eugénisme et le clonage, la décadence du monde occidental causée par le libéralisme économique et sexuel dont il analyse le pacte sous la forme du tourisme sexuel, la portée négative des valeurs de mai 68, l'émergence de nouvelles formes de violence en Occident, etc.. 
Par ailleurs, il mise sur le duo choc et spectacle, mixant ${ }^{36}$ humour et désespoir ${ }^{37}$. Pour ne citer que deux exemples, on peut lire dans Les Particules élémentaires: "La pouffiasse karmique [...] conclut par ces phrases: '[...] Je vous demande de vous ouvrir sur l'espace illimité de la création. - Poil au fion' songea rageusement Bruno." (Houellebecq, 1998: 137). Ce même Bruno qui, dans la seconde séance d'écriture du Lieu du changement produit ce poème: “Je bronze ma queue / (Poil à la queue!) / À la piscine/ (Poil à la pine!) / Je retrouve Dieu / Au solarium, / II a de beaux yeux, / II mange des pommes. / Où il habite? / (Poil à la bite!) / Au paradis / (Poil au zizi!)" (idem: 138-139). Dans La Possibilité d'une île, on trouve: "Longue et confuse, l'histoire de la Première Diminution n'est aujourd'hui connue que de rares spécialistes, qui s'appuient essentiellement sur la monumentale Histoire des Civilisations Boréales, en vingt-trois tomes, de Ravensburger et Dickinson." (Houellebecq, 2005: $446^{38}$ ).

Michel Houellebecq est bel et bien un maître de la dérision. Pourtant, des critiques tels qu'Eric Naulleau ne voit pas d'humour dans l'œuvre de Michel Houellebecq, mais plutôt du ricanement. (cf. Naulleau, 2005: 119). Ce n'est pas un hasard s'il est considéré comme le romancier le plus corrosif de sa génération, car il privilégie la provocation, le cynisme, mais aussi l'ambiguïté.

La provocation et l'ambiguïté sont des procédés houellebecquiens et chessexiens qui ne se restreignent pas à leur univers romanesque. Au contraire, ils trouvent des bases solides dans leurs apparitions publiques et controverses. Ils aiment, tous deux, semer le flou entre le réel et l'imaginaire, le biographique ${ }^{39}$ et le fictionnel, l'auteur et les narrateurs/personnages. Les personnages masculins de Chessex sont souvent la projection plus ou moins directe de l'auteur, par exemple. La fiction houellebecquienne est aussi nourrie par les déclarations sulfureuses de l'auteur lors de ses apparitions publiques. Cellesci lui ont d'ailleurs valu une procédure pénale en 2001, après une interview accordée à la revue Lire, dans laquelle, entre autres choses, il se déclarait ouvertement islamophobe. Chez les deux écrivains, le lecteur fait souvent face à l'abandon de l'univocité et de la signifiante, même si Houellebecq, en comparaison, est beaucoup plus cru et grossier - par provocation? -, alors que Chessex préfère un langage plus feutré.

\footnotetext{
${ }^{36}$ Ce terme, issu du monde audiovisuel, est ici utilisé à dessein.

37 Joël Schmidt parle d' "humour du désespoir" présent dans les auteurs actuels, "joyeux et farceurs et qui se plaisent à l'ironie contre le conformisme, l'ennui de nos sociétés et de nos travers." (Schmidt, 1997: 143). D'autres, comme Nancy Huston, rangent Houellebecq parmi les professeurs de désespoir qui ont marqué la littérature (Huston, 2004). Retenons que ce romancier est tout à fait d'accord avec cette thèse qui le place dans une lignée post-schopenhauerienne. Par contre, il n'admet pas le titre de nouveau réactionnaire dont l'a affabulé Daniel Lindenberg (Lindenberg, 2002), puisque, dans ses romans, il existe l'idée que toute mutation est irréversible. (cf. http://www.dailymotion.com/video/x6s2q3_houellebecq-les-particules-elementa_creation).

${ }^{38}$ C'est nous qui soulignons.

${ }^{39}$ Ce qui rejoint l'idée de "vieuvre", concept d'Antoine Compagnon (Compagnon, 1983), où l'on peut résoudre la tension entre fiction et réalité, en expliquant l'œuvre par la biographie.
} 
Pourtant, à en croire Pierre Jourde, ces options d'écriture correspondent aux règles qui régissent le champ littéraire contemporain: un livre doit être un roman, être réaliste, être vécu ${ }^{40}$ et être audacieux ${ }^{41}$ (cf. Jourde, 2002: 15-18). Règles que Michel Houellebecq et Jacques Chessex complètent avec le pouvoir de tout dire et d'écrire sur tout, piétinant sur les tabous d'antan ${ }^{42}$. En effet, aux yeux de l'historien Alain Besançon, les caractéristiques de la contemporanéité ont aidé à la réception d'écrivains comme Michel Houellebecq. Pour l'auteur de "Houellebecq, critique de l'ouvrage Plateforme", le succès de ce romancier se doit probablement à une autre raison: "c'est la rupture en un point du couvercle politically correct. Ce n'est pas que les Français pensent mal, mais ils ne supportent plus qu'on les force à penser bien." (Besançon, 2002: 6) ${ }^{43}$. Un lecteur anonyme aura commenté: "Où est le bec, c'est un malin qui a compris qu'il fallait qu'il soit plus célèbre que ses livres. [...] Pour faire parler de soi, finalement, il n'y a que deux recettes: parler de ses histoires de $Q$ [...] ou alors cracher du venin, n'importe lequel." (apud Willems, 2005: 55-56).

A quoi Houellebecq semble répondre: "Je ne sais pas si c'est une bonne chose de choquer... En tout cas, c'est une source d'emmerdements." (apud Sénécal, 2001). II en vient même à se déresponsabiliser en affirmant dans une interview dirigée par Josyane Savigneau: "J'aimerais que ce que je pense, moi personnellement, n'ait aucune importance. C'est le sens de l'époque qui cherche à m'entraîner dans la polémique. [...] Cela dit, il semble que j'aie une espèce de flair de cochon pour déceler ce qui va faire mal à la société autour de moi." (apud Savigneau, 2001). Dans un entretien avec Fabio Gambero ${ }^{44}$, Houellebecq explique que la provocation n'est pour lui qu'un passe-temps innocent et un moyen de manipuler les médias avides. Dans une autre interview menée par Dominique Rabourdin, Houellebecq dénie rechercher la provocation à dessein:

Rabourdin: Vous n'avez pas l'impression d'exploiter un certain nombre de recettes? Michel Houellebecq: Je ne crois pas.

\footnotetext{
${ }^{40}$ C'est-à-dire qu'il existe une prédominance du récit autobiographique. A ce propos, Pierre Jourde observe que "l'effacement contemporain des frontières entre roman et autobiographie, qui a donné naissance à des genres hybrides tels que l'autofiction', favorise l'équivoque, et l'identification émotionnelle du récit à la personne de l'écrivain." (Jourde, 2002: 17). C'est exactement ce qui se passe avec Michel Houellebecq et Jacques Chessex.

${ }^{41}$ Pierre Jourde précise que "l'audace consiste à faire toujours la même chose. Du témoignage, et aussi de la violence ou du sexe. Si possible les trois. [...] On ne fait plus guère lire qu'avec cela." (Jourde, 2002: 18). Encore une fois, Michel Houellebecq et Jacques Chessex correspondent à cette option modale et thématique d'écriture.

${ }^{42}$ Selon Pierre Jourde, "Certains continuent à se demander si l'on peut tout dire. Le 'tout' s'avère n'être qu'un argument publicitaire, pour deux raisons: d'abord parce que toutes les limites ont été franchies depuis longtemps: [...] Sade, Rebell, Apollinaire, Céline, etc. Ensuite et surtout parce que le 'tout' en question, dont on fait si grand cas, s'avère à la lecture n'être qu'une anodine histoire de fesses dont il est aussi ridicule de s'extasier que de se gendarmer." (Jourde, 2002: 18-19).

${ }^{43}$ Alain Besançon ajoute: "or avec les 'valeurs', les interdits, les 'tabous' [...] Houellebecq, il faut bien le dire, y va fort. Le public prend ces pétards pour les signaux avant-coureurs d'une libération: sera-t-il enfin interdit d'interdire? Peut-être eût-il été souhaitable que, de cette première fissure dans le couvercle, fuse un air plus pur." (Besançon, 2002: 6-7).

${ }^{44}$ GamBERO, Fabio (1999). "Le romancier qui divise la France (trad. de M.Lévy)" [La Reppublica, 17 mai 1999] [en ligne]. [consulté le 16/08/2007] <URL: http://www.houellebecq.info/presse.php3>.
} 
Rabourdin: Vous provoquez délibérément?

Michel Houellebecq: Provoquer? Non. J'ai un sens moral très développé... Je n'hésite pas à prendre des positions morales sur les vrais sujets sérieux. II y a de ma part un désir de changer les choses et l'Histoire, peu à peu, me donnera raison. Regardez en trois ans les progrès du clonage humain. Ayant raison, je vaincrai. C'est une question d'années. (Rabourdin, 2007: 37).

Pourtant, d'aucuns pourront légitimement pointer dans l'écriture houellebecquienne l'exagération qui frôle le scandaleux II est question, en vérité, de caricature. Dans son article "Je suis l'écrivain de la souffrance ordinaire" (Houellebecq, 2001b: 27), Michel Houellebecq avoue aussi que l'invective est l'un de ses plaisirs. L'ironie mordante, le cynisme sont caractéristiques de son écriture ${ }^{45}$.

Afin d'appâter l'attention du public, Michel Houellebecq brave le "politiquement correct", en choisissant plusieurs stratagèmes. Son écriture écrue est, par exemple, replète de clichés xénophobes - mais aucunement chauvins - à ne pas imputer à l'auteur. En effet, voulant rendre compte de son époque, Michel Houellebecq place ces clichés dans la bouche de ses personnages, afin de démontrer comment pensent certains de ses contemporains.

En outre, Michel Houellebecq est un champion incontesté du name-dropping, mélangeant littérature et people, fiction et réalité, art et show-business, ce qui est dérangeant pour certains. Jacques Chessex, plus modéré, s'amusait, dans ses romans, à faire entrer malicieusement des figures littéraires telles que Benjamin Constant (L'imitation, 1998), Marcel Arland (Monsieur, 2001) ou Roger Vailland (L'éternel sentit une odeur agréable, 2004) ${ }^{46}$. Des références culturelles que d'aucuns, comme Charles Edouard Racine (Racine, 1997) considèrent comme une présomption de la part de Chessex qui utiliserait ce procédé afin de faire croire à une parenté artistique qui l'unirait à de glorieux prédécesseurs convoqués dans ses trames romanesques.

\section{Conclusion}

Nous pouvons alors conclure que Michel Houellebecq et Jacques Chessex, au détriment de leur éloignement géographique, biographique et stylistique, partagent une réputation de persona non grata causée par leur écriture et leur posture sociale politiquement incorrectes. Ils ont tous deux utilisé leur plume comme un acte d'irrévérence sociale" axé sur ce qu'il ne "convient pas socialement d'écrire", en parallèle avec une posture

\footnotetext{
${ }^{45}$ Ce ne sont pas, évidemment, les seules qualités de son style.

${ }^{46}$ En guise d'illustration, une brève liste des figures du monde référentiel réel citées dans les romans chessexiens a été établie par Charles-Edouard Racine (Racine, 1997: 30). Ainsi, dans La mort d'un juste, publié chez Grasset en 1997, pas moins de 42 écrivains, 8 peintres et 18 musiciens sont-ils évoqués, ou apparaissent même comme personnages furtifs ou persistants. Et toujours, nous dit Racine, pour satisfaire à un cliché.
} 
médiatique sui generis. En plus de l'“horribile dictu" et l'“horribile visu", nous avons droit, avec ces deux auteurs, à l'“horribile scriptu”.

Leur inconvenance est surtout ressentie par leurs compatriotes, alors qu'à l'étranger, leurs propos polémiques sont souvent minorés. Ainsi, l'œuvre de Michel Houellebecq, même s'il tire sur tout le monde, est plutôt refermée sur la réalité sociétale française et des référents réels de l'Hexagone. Plusieurs invectives peuvent même passer inaperçues pour le lecteur qui ne connaît pas la société française actuelle - un défi pour ses traducteurs. Car l'œuvre houellebecquienne est profondément datée: c'est une géochronologie dérangeante d'un stade, d'un moment déterminé de l'histoire française. II bénéficie alors d'une meilleure réception à l'étranger.

La polémique de cet auteur est enflammée par sa posture médiatique. Les médias sont, pour lui, au service de la société du spectacle, des variétés et des people, où se mélangent vie publique et vie privée, où s'entremêlent fiction et réalité et où l'ambiguïté est déconcertante. Mais même si Michel Houellebecq aime la dissimulation, il fait aussi de l'autodérision, comme le prouve son dernier roman La carte et le territoire (Houellebecq, 2010).

Jacques Chessex, même s'il se tourne aussi en dérision, préfère la voie de la littérature de l'aveu, que se soit dans ses livres qui frisent le scandale ou dans ses récits autobiographiques où il raconte, haut et fort, ses vices, comme dans Carabas (Chessex, $1971)^{47}$. Le scandale de ces aveux ne tient pas uniquement de l'immoralité des actes commis; outre l'absence de remords ou de faute (avec quelle légèreté narre-t-il ses aventures infidèles ${ }^{48} \ldots$ ), ce sont surtout le ton fier, vantard et l'air de défi qui dérangent les esprits bien-pensants qu'apostrophe l'auteur:

Oui je me suis battu avec toutes sortes de gens, oui j'ai été arrêté, oui j'ai fait du tapage et du scandale et c'est là que vous m'attendez, mes canetons chéris, car je me débattais entre les mains de vos flics pendant que vous bridgiez et que vous rosissiez de confusion en relisant votre premier article du Peuple. Oui, cent fois oui, l'alcool libérait ma violence, et ma violence vous embêtait. (Chessex, 1971: 26).

La violence de Chessex (tout comme son orgueil et sa susceptibilité) est déjà légendaire: il ne la cachait point, il en était satisfait; profondément ancrée en lui, elle constituait aussi la force de sa personnalité: "Ma violence n'est ni un défi ni un passe-temps. Encore moins un jeu de l'esprit. Elle me constitue. Elle est ma matière première, ma nature, l'esprit de cette matière et de cette nature. Violence dans la chair, et violence dans l'intelligence que porte

\footnotetext{
${ }^{47}$ Lire, à cet égard, Chessex, 1971: 12. Certains de ces épisodes sont repris dans d'autres chapitres, comme celui de "Dieu, la mort" (Chessex, 1971: 211-213).

${ }^{48}$ Lire, par exemple, "Le ciel assiste le pauvre pèlerin" (Chessex, 1971: 173-184).
} 
cette chair." (Chessex, 1971: 151). Néanmoins, comme beaucoup pourront le témoigner (Michel Audétat, Lionel Baier, Gilbert Salem, Jacques de Decker, par exemple), derrière cette image d'ours, Chessex était beaucoup plus aimable, affectueux et généreux qu'on ne pourrait le penser. Chessex le revendiquait lui-même dans son Monsieur. "On a beaucoup mythifié l'énergumène Chessex. Je suis beaucoup plus poli, policé que mes ennemis veulent le faire croire." (Chessex, 2001: 32).

Par ailleurs, Chessex s'est aussi livré à des aveux que rejoignent l'amertume, le regret, le remords, comme Dans la buée de ses yeux ${ }^{49}$ (Chessex, 1995), Portrait d'une ombre $^{50}$ (Chessex, 1999), sa "Lettre à mes fils" ${ }^{51}$ dans Monsieur (Chessex, 2001) ou Pardon mère ${ }^{52}$ (Chessex, 2008). L'aveu, en effet, est "la modalité selon laquelle Jacques Chessex écrit - selon laquelle il est lu.

Or, la polémique de cet auteur fut aussi enflammée par sa posture sociale immorale (l'alcool, les femmes ${ }^{53}$, la violence...), alors que les médias ont surtout servi à diffuser son œuvre.

Son "politiquement incorrect" est surtout ressenti en Suisse, certes, mais il dérange plus à l'étranger que ne le fait celui de Houellebecq. Ceci parce que son œuvre a une portée universelle, même si elle raconte des récits de vies de Romands qui se déroulent en Suisse. Des histoires où rares sont les personnages au référent réel; la plupart sont anonymes. Par ailleurs, l'œuvre chessexienne a une valeur intemporelle, car peu de ses histoires peuvent être datées.

\footnotetext{
${ }^{49}$ II s'agit de vingt-trois petits chapitres qui racontent les sentiments de Chessex envers Myriam Matossi (poète et peintre), de leur première rencontre $\left(1^{\text {er }}\right.$ mai 1966) à la fin de leur relation aujourd'hui. Elle est caractérisée comme envoûtante par ses yeux gris, mais ne pouvant être heureuse puisqu'elle porte en elle le traumatisme d'une enfance sans père et d'une mère plutôt absente. Elle écarte, sans le savoir, l'amour de Chessex, de peur de le perdre et lui reproche de l'abandonner à la faveur de ses livres, etc. C'est M., comme il l'appelle la plupart du temps dans ses livres et dans cette chronique, qui a sauvé Chessex de ses mauvaises habitudes d'alcoolique et du poids de la culpabilité du suicide de son père...

${ }_{50}$ Texte élégiaque en prose, en alternance avec des petits poèmes où Jacques Chessex raconte le vide laissé dans sa vie par le suicide de son père, vingt ans auparavant (en 1956). II parle aussi du remords de ne pas lui avoir montré qu'il l'aimait, et explique que le père est devenu le fils de son fils, puisque c'est par l'écriture que Chessex va faire revivre son père, va maintenir vivante sa mémoire.

${ }^{51}$ Jacques Chessex y avoue le mauvais père qu'il a été. Dans le salon de Ropraz, le bureau, Chessex avait des toiles de son fils François, 22 ans, étudiant aux Beaux-arts. Jean filme et écrit. Sur eux, Chessex écrivit: "Maintenant, c'est moi qui dois les mériter". II a cru les perdre lorsque leur mère a quitté Ropraz, les emmenant, en 1986: "Je vous ai aimés, François et Jean, de façon maladroite et absolue, en profondeur, en votre absence [...]. Sur le reste, la rigueur et l'étonnement au travail, l'entretien du corps, le plaisir, et le plaisir à la paresse, je n'ai rien à vous enseigner ou à vous rappeler que vous ne sachiez déjà. [...] Ma seule crainte [...] est de vous peser, vieux, vieillard. [...] Mon vœu: aidez-moi à mourir avant.". Sans le savoir, Jacques Chessex verrait son désir réalisé...

52 Livre déjà résumé dans notre article.

53 Son infidélité conjugale liée à son désir de liberté lui a, par exemple, valu deux divorces: “J'ai été marié huit ans. C'était un premier mariage [avec Michelle] - ensuite il y en a eu un autre [avec Elisabeth], et un second divorce aussi. Je me suis assez entendu reprocher mon instabilité pour en avoir la nausée. Je ne suis pas du tout instable: je n'avais pas ce que je voulais, j'étais inquiet, volé, usé pour rien, à cause de cela mal dans ma peau et mécontent. Instabilité donc, au dire de mes proches, ingratitude, aveuglement, velléité, lâcheté, légèreté, infidélité." (Chessex, 1971: 31). Le 21 août 1967, Chessex s'était aussi marié à une Marinette pendant des vacances en Angleterre. A leur retour, ils ont divorcé (cf. Chessex, 1971: 185-192).
} 
Le scandale de Jacques Chessex est qu'il montre à l'étranger ce que les Suisses veulent cacher. Houellebecq, de son côté, montre aux Français ce qu'ils répugnent ou se refusent à voir. Tous deux diffusent, il est vrai, une image bien gênante de leurs compatriotes. Mais écrire n'est-ce pas révéler, comme le prônait Sartre? Ce même philosophe qui défendait le fait que l'écrivain donne à la société une conscience malheureuse...

L'embarras est surtout amplifié par le poids médiatique et la renommée littéraire qu'ils ont pu acquérir, chacun à sa manière. Malgré cela, il est important de rappeler aussi que ces deux auteurs n'ont pas toujours été politiquement incorrects. En effet, dans les deux cas, il existe une évolution vers la norme, la bien-pensance...

Après avoir aidé Michel Houellebecq à atteindre le sommet de la célébrité, les invectives de cet écrivain s'estompent: son dernier roman La carte et le territoire, dépouillé du ton cru et provocateur de ses prédécesseurs, est fort convenable... aux règles de la bienséance. La promotion médiatique du livre l'emporte sur celle de l'auteur qui est devenu bien sage. Mise à part une accusation de plagiat de Wikipédia dans plusieurs passages, on ne lit que des critiques élogieuses. A se demander s'il s'agit bien d'un livre de Houellebecq.

Quant à Jacques Chessex, nous reproduisons ici le commentaire de Jérôme Garcin en 2005:

On a connu le marquis de 'Carabas' au milieu des années 1970. II avait la rondeur cuivrée et les bacchantes humides de son maître Flaubert. II buvait beaucoup, avait faim [...] de chair fraîche et de prose riche. Le mystique a succédé au bacchique. [...] II se désencombre du trop-plein. II aspire à la légèreté $[\ldots]$ à 'un état de transcendance'. (Garcin, 2005).

Néanmoins, la bête ne dormait que d'un œil. Jacques Chessex a continué à produire, jusqu'à sa mort, des récits gênants qui perpétuent sa réputation de fâcheux personnage et d'écrivain politiquement incorrect. À l'inverse, Houellebecq serait-il un "Mutin de Panurge", jeu de mots de Philippe Muray, à la tonalité rabelaisienne, pour identifier les individus dont la rébellion est factice et en accord avec le temps? Ou, au contraire, continuera-t-il à s'afficher comme un individu assez méprisable, tel qu'il se présentait dans sa correspondance avec Bernard-Henri Lévy, dûment intitulée Ennemis Publics (Houellebecq et Lévy, 2008)? Histoire à suivre... 


\section{Bibliographie}

ALTHES, Liesbeth Korthals (2004). "Persuasion et ambiguïté dans un roman à thèse postmoderne (Les Particules élémentaires)". In: WESEMAEL, Sabine van. Michel Houellebecq. Études réunies par, avec une interview inédite de l'auteur. Amsterdam/New-York: Rodopi, pp. 29-46.

ARMEL, Aliette (2007). "Jacques Chessex, autoportrait d'un hérétique". In: Le Magazine Littéraire, nㄴ63, avril 2007, pp. 90-95.

BESANÇON, Alain (2002). "Houellebecq, critique de l'ouvrage Plateforme". In Commentaire, no96 [Commentaire, no96] [en ligne]. [consulté le 12/04/2009] <URL: http://www.asmp.fr>.

BRIDEL, Geneviève (2002). Jacques Chessex. Transcendance et transgressions: entretiens. Lausanne: Bibliothèque des Arts.

BURGELIN, Claude (2003). "Donner son corps à la littérature? Brèves remarques sur l'écrivain et son image en l'an 2000". In: LOUETTE, Jean-François et ROCHE, Roger-Yves (dir). Portraits de l'écrivain contemporain. Seissel: Editions Champ Vallon, pp. 47-58.

ChesseX, Jacques (1969). Portrait des Vaudois. Paris: Actes Sud, Labor, L’Aire [ed. de 1982].

CHESSEX, Jacques (1971). Carabas. Lausanne: Cahiers de la Renaissance Vaudoise.

CHESSEX, Jacques (1988). "Notice biographique". In GARCIN, Jérôme (dir). Dictionnaire des écrivains contemporains de langue française par eux-mêmes. Paris: Mille et une nuits. [en ligne]. [consulté le 20/09/2010] <URL: http://bibliobs.nouvelobs.com/20091010/15206/jacques-chessex-par-luimeme>.

CHESSEX, Jacques (1997). Avez-vous déjà giflé un rat. Un pamphlet. Yvonand: Bernard Campiche Editeur.

CHESSEX, Jacques (2001). Monsieur. Paris: Grasset.

CHESSEX, Jacques (2005). Le désir de Dieu. Paris: Grasset.

CHESSEX, Jacques (2007). Le vampire de Ropraz. Paris: Grasset.

CHESSEX, Jacques (2008). Pardon mère. Paris: Grasset.

CHESSEX, Jacques (2009). Un juif pour l'exemple. Paris: Grasset.

CHESSEX, Jacques (2009b). Le dernier crâne de M. de Sade. Paris: Grasset.

Compagnon, Antoine (1983). La troisième République des Lettres. Paris: Seuil.

DANTHE, Michel (2009). "Carnaval de Payerne, Jacques Chessex réclame justice" [Le Matin, 20 mars 2009] [en ligne]. [consulté le 01/10/2010]

<URL:http://webcache.googleusercontent.com/search?q=cache:http://www.lematin.ch/actu/suisse/ carnaval-payerne-jacques-chessex-reclame-justices.

FroIdeVAuX, Gérald (1998). “Jacques Chessex”. In: FrANCILLON, Roger (dir). Histoire de la littérature en Suisse romande, de la Seconde Guerre aux années 1970, vol.3. Lausanne: Editions Payot Lausanne, pp.404-414.

GARCIA, Laure (2009). "Avec les Écrivains du Sud" [Le Nouvel Observateur, 02 avril 2009] [en ligne]. [consulté le 19/10/2010] <URL:http://bibliobs.nouvelobs.com/blog/bd-lauregarcia/20090402/11665/avec-les-ecrivains-du-sud>.

GARCIN, Jérôme (2003). "Retrouver Chessex". In FroideVAUX, Gérald et MichaUd, Marius (dir) (2003). Jacques Chessex: il y a moins de mort lorsqu'il y a plus d'art. Lausanne: Bibliothèque des Arts.

GARCIN, Jérôme (2005). "L'ermite de Ropraz" [Le Nouvel Observateur, 24 mars 2005] [en ligne]. [consulté le 19/10/2010] <URL: http://bibliobs.nouvelobs.com/20091010/15214/lermite-de-ropraz>.

HouellebeCQ, Michel (1994). Extension du domaine de la lutte. Paris: Maurice Nadeau.

HouellebecQ, Michel (1997). Rester vivant et autres textes. Paris: Flammarion, col. Librio.

HOUELLEBECQ, Michel (1998). Les particules élémentaires. Paris: Flammarion.

HouellebeCQ, Michel (2001). Plateforme. Paris: J'ai Lu. 
HOUELLEBECQ, Michel (2001b). "Je suis l'écrivain de la souffrance ordinaire". In Le Figaro, 4 septembre 2001, p.27.

HOUELLEBECQ, Michel (2005). La possibilité d'une île. Paris: Fayard.

HouelLebeCQ, Michel (2010). La carte et le territoire. Paris: Flammarion.

HouellebeCQ, Michel et LeVY, Bernard-Henri (2008).Ennemis publics. Paris: Flammarion-Grasset.

Huston, Nancy (2004). Professeurs de désespoir. Paris: Actes Sud.

JatON, Anne-Marie (2001). Jacques Chessex, La Lumière de L'Obscur. Genève: Editions Zoé.

JOURDE, Pierre (2002). La littérature sans estomac. Paris: L'Esprit des Péninsules.

Naulleau, Eric (2005). Au secours, Houellebecq revient. Paris: Chiflet \& Cie.

NogueZ, Dominique (2005). Houellebecq, en fait. Paris: Fayard.

PATRICOLA, Jean-François (2005). Michel Houellebecq ou la provocation permanente. Paris: Ecriture.

RABOURDIN, Dominique (2007). "Pour moi, le sexe et la transgression n'ont rien à voir' Propos de M. Houellebecq". In: Le Magazine Littéraire, №470, décembre 2007, pp.35-37.

RACINE, Charles-Edouard (1997). L'imposture ou La fausse monnaie. Un essai de critique littéraire: les romans de Jacques Chessex. Lausanne: Antipodes.

Savigneau, Josyane (2001). "Houellebecq et l'Occident". In: Le Monde, 31 août 2001.

SCHMIDT, Joël (1997). "Éclatement du roman français". In: SALGAS, Jean-Pierre et SCHMIDT, Joël (1997). Roman français contemporain. Paris: ADPF, pp.119-175.

SCHOBER, Rita (2004). "Vision du monde et théorie du roman: concepts opératoires des romans de Michel Houellebecq". In: BlanckEman, Bruno, MuRA-Brunel, Aline et DAMBRE, Marc (dir) (2004). Le roman français au tournant du XXème siècle. Paris: Presses Sorbonne Nouvelle, pp.505-515.

SENECAL, Didier (2001). "Michel Houellebecq”. In: Lire, no298, septembre 2001.

WiLLEMS, Isabelle (2005). Michel Houellebecq au milieu du monde. Ce qu'un roman fait à la société. Mémoire de licence en Sociologie. Institut des Sciences Humaines et Sociales: Université de Liège. 